\title{
X Congresso Brasileiro de Enfermagem Oncológica/ VII Jornada de Enfermagem do INCA
}

Data: 29, 30 de setembro e 1 de outubro de 2010 Local: Federação das Indústrias dos Estado do Rio de Janeiro (Firjan) Av. Graça Aranha, 1 - $13^{\circ}$ andar - Centro (RJ), Brasil 


\title{
A Trajetória Histórica do Ensino da Oncologia no INCA nos anos 1980: Perspectivas para o Saber da Enfermagem
}

\author{
Souza MCF \\ Educação Continuada da Divisão de Enfermagem/HCl/INCA, Brasil \\ Almeida Filho AJ \\ Departamento de Enfermagem Fundamental da EEAN/UFRJ, Brasil
}

\begin{abstract}
Resumo
Introdução: Desde as primeiras décadas do século XX, o câncer era motivo de preocupação das autoridades públicas e da saúde. Desse modo, políticas para diagnóstico, tratamento, controle e prevenção foram adotadas. O INCA, responsável pela assistência oncológica, foi cenário de intenso investimento na especialização da Enfermagem em Oncologia. Objeto: Ensino da Oncologia no INCA no período da cogestâo. Objetivo: Descrever as estratégias para reatualizar o habitus profissional de enfermeiros em Oncologia no INCA. Metodologia: Estudo histórico-social. Fontes primárias: artigos, livros comemorativos, boletins informativos do INCA e Revista Brasileira de Cancerologia. Fontes secundárias: livros e trabalhos em oncologia, política social, de educaçáo e saúde. Utilizou-se o referencial teórico de Pierre Bourdieu, empregando o conceito de capital científico. Resultados: Com a implantação da cogestão entre o Ministério da Saúde, Ministério da Previdência e Assistência Social e INCA, coube a este último a responsabilidade pela normatização das açôes de controle do câncer no Brasil, tendo como atribuiçóes a elaboração de modelos assistenciais e o desenvolvimento de programas educativos, com a participação das enfermeiras atuando efetivamente no campo da Enfermagem Oncológica Brasileira, e a implantação da Residência de Enfermagem em Oncologia. Consideraçốes Finais: Neste período, ampliou-se a produção e divulgaçáo de conhecimentos sobre o câncer, nos cursos, nas pesquisas e na publicação da Revista Brasileira de Cancerologia, revelando preocupação pela disseminação científica, deixando implícita a capacidade de liderança que o INCA podia desenvolver em âmbito nacional, contribuindo para definir suas possibilidades nesse campo e distinguindo-o como uma Instituição que produz, reproduz e difunde o conhecimento da Oncologia.
\end{abstract}




\title{
Estresse Laboral, Coping e Enfermagem Oncológica: uma Revisão Bibliográfica
}

\author{
Lopes M, Gherardi-Donato ECS
}

Escola de Enfermagem de Ribeirão Preto da Universidade de São Paulo. Ribeirão Preto (SP), Brasil

\section{Resumo}

Introduçáo: A vivência de situaçóes emocionais desgastantes pode conduzir o profissional ao estresse ocupacional, o qual se utiliza de mecanismos de coping para tentar superar uma situação ou agente estressor. Objetivo: Descrever e analisar as publicaçóes científicas nacionais disponíveis gratuitamente na Internet, referentes à temática estresse laboral do enfermeiro em Unidades Oncológicas, e seus mecanismos de coping. Metodologia: Revisão eletrônica da literatura nas bases de dados Bireme (Lilacs, BDENF e SciELO) de 26/julho a 1 agosto/2010, considerando acesso livre, texto completo e em português. Nas bases de dados Lilacs e BDENF, foram identificados 147 artigos com os descritores: "estresse, coping, enfermagem e enfermagem oncológica", porém 19 artigos foram considerados. Já na SciELO, foram encontrados 35 artigos, mas selecionados 19 artigos. Entretanto, finalizou-se em 21 artigos de acordo com a leitura dos títulos e resumos. Resultados: Os fatores estressantes no ambiente de trabalho são: óbito dos pacientes; situações de emergência; problemas de relacionamento com a equipe de enfermagem e situaçóes relacionadas ao processo de trabalho. Já as estratégias de coping foram: reavaliação positiva (focado na emoção); resolução de problema e autocontrole, além de evitamento, confronto direto e confronto indireto. Encontramos ainda instrumentos para mensuração do estresse ocupacional, avaliação de intervenção em estresse ocupacional e mensuração de coping no ambiente de trabalho. Conclusão: Conhecer os agentes estressores do Setor de Oncologia, as estratégias de enfrentamento disponíveis e efetivas, para lidar com situaçóes adversas, permite planejar e implementar açôes que visam ao bem-estar tanto do profissional quanto da organização do ambiente de trabalho. 